\title{
Rugby-playing history at the national U13 level and sub- sequent participation at the national U16 and U18 rugby tournaments
}

\author{
Justin Durandt ${ }^{1}$ BSc (Med)(Hons) Exercise Science (Biokinetics) \\ Ziyaad Parker ${ }^{2}$ BSc (Med)(Hons) Exercise Science (Biokinetics) \\ Herman Masimla ${ }^{3}$ (BA, HDE) \\ Mike Lambert ${ }^{2}(\mathrm{PhD})$ \\ ${ }^{1}$ Discovery Health High Performance Centre, Sports Science Institute of South Africa, Newlands, Cape Town, South Africa \\ ${ }^{2}$ MRC/UCT Research Unit for Exercise Science and Sports Medicine, Department of Human Biology, Faculty of Health Sciences, \\ University of Cape Town, South Africa \\ ${ }^{3}$ South African Rugby Union, Newlands, Cape Town, South Africa \\ Correspondence to: Justin Durandt (jdurandt@ssisa.com)
}

\begin{abstract}
Background. The South African Rugby Union has adopted the model of competition at a young age (U13 years) to identify talent. There is concern however that bigger players who mature early are selected at this age, and that the majority of these players do not play rugby at a high level after puberty.

Objectives. The aim of this study was to establish how many players in the 2005 U13 Craven week ( $n=349$ ) participated in subsequent U16 Grant Khomo and U18 Craven week tournaments. Design. Longitudinal.

Results. $31.5 \%$ of the players who played in the U13 Craven week, were again selected to play at U16 Grant Khomo week and $24.1 \%$ were selected for the U18 Craven week.

Conclusion. Seventy-six per cent of the players selected for the U13 tournament do not play at the U18 national Craven week tournament. These data need to be considered when decisions are made about the cost-effectiveness of staging the U13 tournament, particularly if the main goal of this tournament is for talent identification.
\end{abstract}

\section{Introduction}

The South African Rugby Union (SARU) hosts four national competition tournaments for junior players (13 - 18 years of age) each year. These tournaments are designed to be the pinnacle of SARU's talent identification and development programme. ${ }^{1}$ The national tournaments are divided into three age groups, U13 Craven week, U16 Grant Khomo week and U18 Craven week and Academy week.

The reason for the first national schools tournament in July 1964 was to bring the top high school boys together to celebrate the 75th anniversary of the South African Rugby board. The tournament was named after the famous Springbok rugby player and coach Dr Danie Craven. The U18 tournament has been held annually since then and is currently rated as one of the top school-boy rugby tournaments in the world. ${ }^{2}$ The tournament has a reputation for identifying and developing talent in South Africa, supported by the fact that several Springboks played in the tournament as schoolboys. ${ }^{3}$

To understand the context of these age group tournaments in relation to talent identification, it is necessary to firstly define this term, as there is currently no consensus on the definition of either talent identification (TID) or talent development (TDE). Therefore for the purpose of this paper the definition used in a recent review of talent identification and development models in sport will be used (p. 403): 'process of recognising current participants with the potential to excel in a particular sport ${ }^{4}$ and TDE is described as 'providing the most appropriate learning environment to realise this potential'.

The first systematic talent identification and development programmes were implemented by the communist countries in the 1960s and 70s. ${ }^{5}$ Other countries, such as China and Australia, used substantial state resources to fund TID and TDE programmes in the 1980 and 1990 s. $^{6}$ These programmes have created the perception held by many parents, coaches and administrators that talented adolescent athletes can be detected or identified by measuring those characteristics that predict success in adult competition. This traditional view has been contradicted in the scientific literature where erroneous assumptions and problems have been identified. ${ }^{4,5}$ For example, the main problem with this model is that most talent identification programmes are directed at the adolescent age group (13 - 18 years), an age which is characterised by much variation as a result of different rates of development. ${ }^{5}$ Furthermore, talent is not simply the measurement of innate abilities, but results from the interaction of these innate abilities with the environment within which the athlete develops. ${ }^{4}$ For these reasons the traditional models, popularised in the 1980s and 1990s, are now being challenged. This has resulted in a general shift towards athlete development rather than talent identification. The model that best encapsulates this shift is the Long Term Athlete Development model (LTAD). ${ }^{7}$ This model was developed by Istvan Balyi ${ }^{7}$ and describes the different stages of physical, mental, emotional and cognitive development of children and adolescents. The main emphasis of this model is to provide more time and opportunities for athletes to develop, especially those athletes who mature at a later stage. In addition, this model provides guidelines on the types of activities related to talent identification and skill acquisition that are appropriate at the different age groups. The LTAD model provides a framework within which each sport discipline can create an athlete development pathway catering for the demands of that sport. 
Early research on talent identification of young rugby players (8 - 13 years) in South Africa showed that talented players could be identified at an early age. ${ }^{8}$ However, this study and a subsequent follow-up study did not track whether these talented young players developed into older talented players, particularly after they had matured through puberty (13-18 years). ${ }^{9}$ In a recent commentary we show how South Africa has 9.4 and 3.7 times as many pre-teen players compared with Australia and New Zealand respectively, yet at a senior level South Africa has only 3.1 and 2.3 times as many players as Australia and New Zealand. ${ }^{10}$ It may be argued that SARU has to place less emphasis on organised talent identification as there is such a large pool of pre-teen players $(n=239614) .{ }^{11}$ With such a large pool of players, the precision and efficiency of the system becomes less important because the expectation is that the talented players will emerge as a result of the competition. It follows that SARU has adopted the approach of organised competition as its main source of talent identification and development. With this approach, and the strong competition between rugby-playing schools, the chances of talented players emerging are very good. However, this approach might also account for the large attrition of players from pre-teens to seniors observed in South Africa, but not in a country such as Australia which places less emphasis on competition at these young ages. ${ }^{12}$

In contrast to the competitive model for young players, adopted by SARU, most experts agree that promoting participation should take precedence over competition at a young age. ${ }^{13}$ Particularly at the U13 level players have different maturation ages. Therefore there is a bias for the coaches to select the bigger boys who may be more mature, but not necessarily more talented. There have been discussions about changing the format of the National U13 tournament and to rather use the resources for activities aimed at player retention and participation (Personal communication: $M$ Green, SARU Development Manager). One of the problems SARU has had in making these decisions is that there is no hard evidence supporting either side of the argument. Therefore the aim of the study was to provide objective data to determine how many boys who played at a U13 national tournament went on to play at the U16 Grant Khomo and U18 Craven week tournaments. We hypothesised that the representation of the U13 players in the older groups would get progressively lower because the factors which determine performance in rugby at an U18 level are not evident at the U13 level and only partially developed by 16 years of age.

\section{Methods}

The study was conducted in the form of a survey and was retrospective in nature. The 2005 U13 Craven week list of players from the SARU database was used for analysis. The year 2005 was selected as this was the first year that all the names of all players attending the week were entered into an electronic database. These names were checked against all the names of all the players attending the U16 Grant Khomo or the U18 Craven week tournaments between 2006 and 2010, using the SARU database. The names were manually sorted to determine representation of the players over the duration of the study. This manual process was checked using the 'vlookup' and 'match' functions in excel. Permission to use the data from the database was obtained from the Faculty of Health Sciences Research and Ethics committee of the University of Cape Town.

\section{Results}

Sixteen teams attended the 2005 U13 Craven week. Each team was permitted to have 22 players $(n=352)$. However, the actual number of players listed on the SARU database was $n=349$ as a result of three teams only having 21 players listed.

Fig. 1 shows that one 2005 U13 player (0.3\%) participated in the U16 Grant Khomo Tournament in 2006, five players (1.4\%) participated in 2007 and 107 players (30.7\%) participated in 2008. The results show that the players had a greater representation in the U16 tournament as their age increased from U14 to U16 over three successive years. Fig. 2 shows that in total 110 (31.5\%) players who played U13 Craven week were selected for U16 Craven week in 2006 - 2008. The totals in Fig. 2 are less than the totals in Fig. 1 because 3 players from 2007 also participated in 2008. As a result of them participating for 2 years in succession they were not counted as repeats in the total.

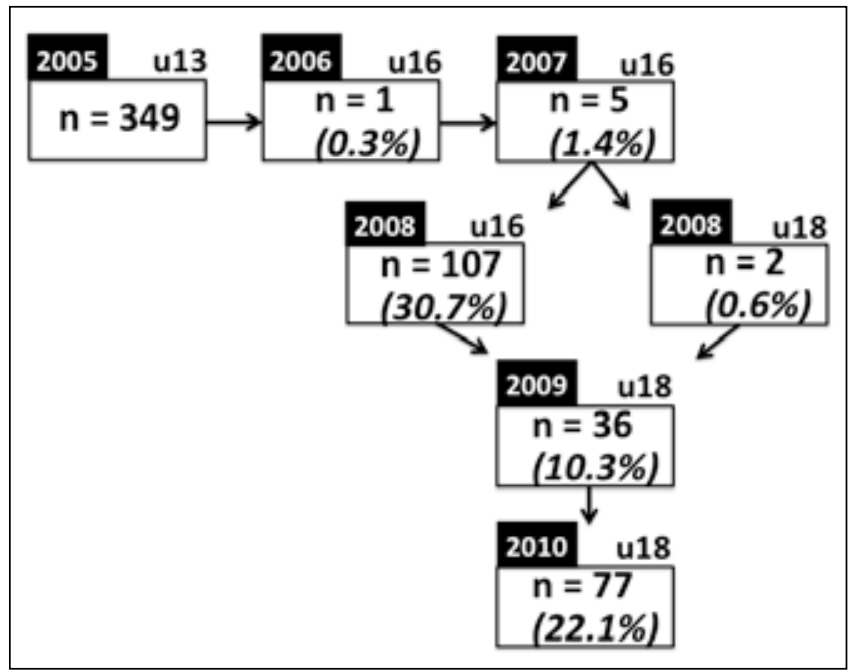

Fig. 1. Number of players from the 2005 U13 tournament who played at subsequent U16 Grant Khomo and U18 Craven week tournaments. The data are expressed as a percentage of the 2005 U13 tournament $(\mathrm{n}=349)$.

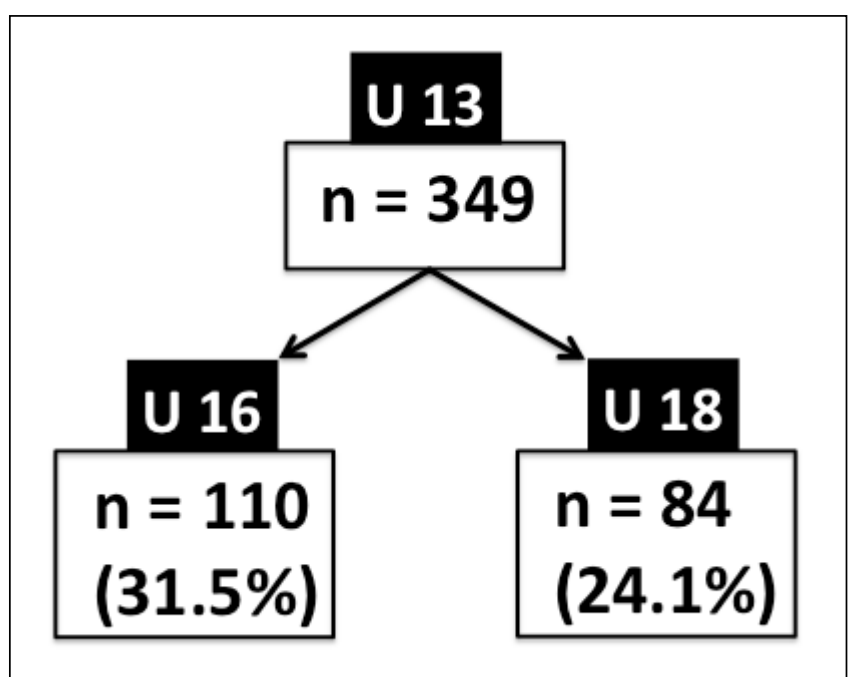

Fig. 2. The total number (and per cent) of the players from the 2005 U13 tournament who played at the U16 Grant Khomo and U18 Craven week tournaments.

Fig. 1 also shows that two players $(0.6 \%)$ from the U13 tournament participated in the U18 Craven week in 2008, 36 players $(10.3 \%)$ participated in 2009 and 77 players (22.1\%) participated in 2010. 
As expected, the number of players participating increased as the players got older. Fig. 2 shows that 84 players $(24.1 \%)$ of the 2005 U13 Craven week players played at the U18 tournament between 2008 and 2010. Only six of the U18 players who played in 2009 did not play in 2010 and only one of the two players who played U18 in 2008 also played in 2009 . Therefore there were a total of 84 players if the non-repeats were added to the 2010 total. The representation decreased by $7.4 \%$ from U16 (31.5\%) to U18 (24.1\%).

\section{Discussion}

The main finding of this study was that the majority of players from the 2005 U13 Craven week were not selected for either the U16 $(69 \%)$ or the U18 Craven week tournament $(76 \%)$ a few years later. These results can be interpreted in one of two ways. Firstly, the attributes that determined success at the U13 level had changed at the U16 and U18 level. A number of studies have measured players of various ages to identify key physiological characteristics associated with performance in rugby. ${ }^{14-16}$ These include body size, aerobic capacity, muscular strength and endurance, speed and muscle power. There is no evidence that the contribution to performance of these key physiological characteristics change with player age, and therefore this explanation cannot account for the poor conversion of success at the $\mathrm{U} 13$ level to success at the $\mathrm{U} 16$ and $\mathrm{U} 18$ levels.

An alternative interpretation is that the U13 players had characteristics associated with success in rugby, but these characteristics changed as the players got older. This is a more likely explanation, particularly since the span from 13 to 18 years encompasses puberty and maturation. It follows that more mature players of the same chronological age (U13) will have an older biological age. These players are more likely to be bigger, faster and stronger ${ }^{17}$ and as a result of these characteristics will perform better than players who are less biologically mature. The late maturers who are talented will not be selected at this age (U13) and may only be selected at a high level after they have matured (U16 or U18). Some of these players may also choose to participate in another sport in which they can excel. ${ }^{18}$ The latter scenario could account for the major attrition that occurs in South African rugby. ${ }^{10}$

These results support the current consensus in the scientific literature that describes the complexities in identifying talent in early adolescence. ${ }^{5} \mathrm{~A}$ recent editorial stated that 'The prediction of long term success is extremely difficult and the later successful athletes are not necessarily the ones who performed best in youth competitions' (p.683). ${ }^{19}$ This is especially true in sports, such as rugby, where body size is related to performance. ${ }^{18,20}$

What practical steps can be taken to address this problem? The first step is to acknowledge that talent identification is a complex process achieved by a combination of physical attributes, skills, attitudes and behaviours. ${ }^{20}$ The next step is to adopt a more pragmatic approach to develop talent from a young age. MacNamara and Colins ${ }^{20}$ highlight the fact that many talent identification programmes operate in resource-challenged environments and that this necessitates the need to establish sports policy against strong evidence-based research. This is true of the South African environment where any programme needs to increase general participation levels and the quality of this participation, while at the same time having clear pathways to elite participation.

In summary, these results suggest that talented young players (U13) do not necessarily become talented older players (U16 and U18). The emphasis placed on talent identification at the young level (U13) may be associated with the high attrition in participation from pre-teen to teens and then senior level in South African rugby. ${ }^{10}$ Changes need to be made to the LTAD programme of SARU considering these data in the revised plan.

\section{RefERENCES}

1. South African Rugby Union. Background To The South African Rugby Football Union (SARFU) and SA Rugby (Pty) Limited. http://www.sarugby. co.za.

2. Rugby365. Craven Week history. website 2009. http://www.rugby365.com

3. Colquhoun A, Grieb E, Heath D. SA Rugby Annual 2009. 38th ed. CTP Books: Parow, Cape Town, 2009

4. Vaeyens R, Lenoir M, Williams AM, Philippaerts RM. Talent identification and development programmes in sport: Current models and future directions. Sports Med 2008;38(9):703-714.

5. Pearson DT, Naughton GA, Torode M. Predictability of physiological testing and the role of maturation in talent identification for adolescent team sports. J Sci Med Sport 2006;9:277-287.

6. Digel $H$. The context of talent identification and promotion: a comparison of nations. New Studies in Athletics 2002;17:13-26.

7. Balyi I, Way R, Cardinal C, Higgs C. Canadian Sport for Life: Long term athlete development resource paper. Vancouver BC: Canadian Sport Centres, 2007.

8. Pienaar AE, Spamer MJ. A longitudinal study of talented young rugby players as regards their skills, physical and motor abilities and anthropometric data. J Hum Mov Stud 1998:34:013-032.

9. Spaamer EJ, Hare EA. A longitudinal study of talented rugby players with special reference to skill, growth and development. J Hum Mov Stud 2001b;41:39-57.

10. Lambert MI, Durandt JJ. Long-term player development in rugby - how are we doing in South Africa? South Afr J Sports Med 2010;22:67-68.

11. International Rugby Board. Website 2010 http//www.irb.com/unions/unions=11000034/index.html.

12. Australian Rugby Union. Kids Rugby. Website 2011 http://www.rugby.com. au/tryrugby/KidsRugby.

13. Way R, Balyi I. Competition is a good servant, but a poor master. Vancouver BC: Canadian Sport Centres, 2007.

14. Deutsch MU, Maw GJ, Jenkins D, Reaburn P. Heart rate, blood lactate and kinematic data of elite colts (under-19) rugby union players during competition. J Sports Sci 1998:16:561-570.

15. Durandt JJ, Du Toit S, Borresen J, et al. Fitness and body composition profiling of elite junior South African rugby players. S Afr J Sports Med 2006;18:38-45.

16. Spamer EJ. Talent identification and development in youth rugby players: A research review. S Afr J Res Sport, Phys Ed and Recreat 2009;31:109118

17. Figueiredo AJ, Goncalves CE, Coelho E Silva MJ, Malina RM. Characteristics of youth soccer players who drop out, pesist or move up. J Sport Sci 2009:27(9):883-891.

18. Malina RM, Pene Reyes ME, Eisenmann JC, Horta L, Rodrigues J, Miller R. Height, mass and skeletal maturity of elite Portugese soccer players aged 11-16 years. J Sport Sci 2000;18:685-693.

19. Elferink-Gemser MT, Jordet G, Coelho-E-Silva MJ, Visscher C. The marvels of elite sports: how to get there? Br J Sports Med 2011:45(9):683-684

20. Coelho-E-Silva MJ, Moreira CH, Concalves CE. Growth, maturation, functional capacities and sport specific skills in 12-13 year old basketball players. J Sports Med Phys Fitness 2010;50:74-181.

21. MacNamara A, Collins D. Comments on 'Talent identification and promotion programmes of Olympic athletes'. J Sport Sci 2011;29(12):1353-1356. 